\title{
Anatomical Dissection of the External Branch of the Superior Laryngeal Nerve to the Laboratory of Anatomy of the Faculty of Medicine of Bamako (Mali)
}

\author{
Abdoulaye Kanté1,2*, Youssouf Sidibé3, Babou Ba², Bréhima Bengaly¹, Bréhima Coulibaly1, \\ Drissa Traoré1, Drissa Ouattara ${ }^{1}$, Mariam Daou4 ${ }^{4}$, Tata Touré ${ }^{2}$, Siaka Diakité2, Moumouna Koné2 \\ Siaka Diallo1, Cheickh Tidiane Diallo², Ousmane Ibrahim Touré1, Birama Togola1, \\ Nouhoum Ongoïba1,2
}

\author{
${ }^{1}$ Service of Surgery B, CHU Point G, Bamako, Mali \\ ${ }^{2}$ Laboratory of Anatomy of the Faculty of Medicine and Odontostomatology, Bamako, Mali \\ ${ }^{3}$ ENT and Head and Neck Surgery Department, CHU Mother-Child "Luxembourg", Bamako, Mali \\ ${ }^{4}$ Service of Neurology, CHU Gabriel Touré, Bamak, Mali \\ Email: ${ }^{\star}$ kanteim@yahoo.fr
}

How to cite this paper: Kanté, A., Sidibé, Y., Ba, B., Bengaly, B., Coulibaly, B., Traoré, D., Ouattara, D., Daou, M., Touré, T., Diakité, S., Koné, M., Diallo, S., Diallo, C.T., Touré, O.I., Togola, B. and Ongoïba, N. (2018) Anatomical Dissection of the External Branch of the Superior Laryngeal Nerve to the Laboratory of Anatomy of the Faculty of Medicine of Bamako (Mali). Forensic Medicine and Anatomy Research, 6, 47-54.

https://doi.org/10.4236/fmar.2018.64005

Received: August 18, 2018

Accepted: September 30, 2018

Published: October 30, 2018

Copyright $\odot 2018$ by authors and Scientific Research Publishing Inc. This work is licensed under the Creative Commons Attribution International License (CC BY 4.0).

http://creativecommons.org/licenses/by/4.0/

c) (i) Open Access

\begin{abstract}
Aim: This study aimed at describing the anatomical variations of the external branch of the superior laryngeal nerve and at estimating the frequency of nerves at risk during the thyroid surgery. Methodology: We realized a forward-looking study from September, 2016 in May 31 ${ }^{\text {st }}, 2018$ in the laboratory of anatomy of the Faculty of Medicine and Odontostomatology of Bamako in Mali. All the fresh anatomical subjects not carrying trauma and or a scar at the level of the previous region of the neck were held. The anatomical subjects were not included presenting a traumatic lesion andlor a scar of the previous region of the neck. Results: We realized 34 dissections of the external branch of the superior laryngeal nerve to 17 deathly subjects ( 11 men and 6 women with a sex-ratio of 1.8). The average age of the subjects was of 42 years (extremes: 18 and 70 years). Our study allowed highlighting in 100\% of the cases, the external branch of the superior laryngeal nerve and the superior thyroid artery so to the right as to the left. On 34 dissected external branch of the superior laryngeal nerve, none had a previous route. However we found 28 nerves $(82.4 \%)$ having a later route, stuck to the external face of the lower constrictor of the pharynx. These were not mixed with the superior thyroid artery and its branch of division and were situated outside the thyroid capsule. In $17.6 \%$ of the cases (6 cases), the nerve had a route mixed in the branch of the superior thyroid artery. These were found inside of the capsule
\end{abstract}


(11.8\% adhered to the artery and $5.8 \%$ crossed its branch of division). Conclusion: The risk of injury of the external laryngeal nerve during thyroid surgery procedure is never zero. It is more important on the left side.

\section{Keywords}

External Laryngeal Nerve, Superior Thyroid Artery, Anatomy, Thyroid Gland, Surgery

\section{Introduction}

The external branch of the superior laryngeal nerve (BENLS), is a mixed nerve, hail, assuring the innervation of the cricothyroid muscle (muscle tensor of vocal cords) [1]. It has an intimate and variable route with the superior thyroid pedicle what explains its vulnerability during the thyroid surgery [2]. Its lesion is responsible for a fatigability of the voice, for a modification of its tone which becomes graver as well as of disorders of the gulp.

This study aimed at describing the anatomical variations of the external branch of the superior laryngeal nerve and at estimating the frequency of nerves at risk during the thyroid surgery.

\section{Materials and Methods}

We realized a forward-looking study from September, 2016 in May 31 $1^{\text {st }}, 2018$ in the laboratory of anatomy of the Faculty of Medicine and Odontostomatology of Bamako in Mali. All the fresh anatomical subjects not carrying trauma and or a scar at the level of the previous region of the neck were held. Were not included the anatomical subjects presenting a traumatic lesion andlor a scar of the previous region of the neck. We proceeded to the dissection of the various superficial, muscular and vascular plans of the previous cervical region. The dissections concerned only the previous region of the neck. The corpse was put in dorsal decubitus with the neck in extension by means of a transverse block inserted under scapula and nape of the neck. The cutaneous sections were the followingones:

- a first horizontal section akin to the mandible going of the protuberance or the eminence chin strap to the angle of the chin;

- the second also horizontal, slightly convex section towards the arm below, going of the manubrium sternal to the collarbone;

- the third vertical section, which leaves the eminence chin strap to the manubrium sternal.

The superficial blade of the cervical fascia was vertically made an incision.

We proceeded then to a wide cutaneous unsticking in the blade of bistoury and by drive going until the outside of the insertions sternal and clavicular below; then mastoid at the top of the sternocleidomastoid. The sternocleidomastoid mus- 
cle was transversely split and its two extremities pulled down at the top and below. The omohyoid muscle was split in his turn, so giving access to the vascular plan. Sternocleidohyoid muscles were reclined to have a good access to the thyroid changing room.

We proceeded to a ligature upstream and downstream to the third way of the internal jugular vein which was cut so giving access to the common carotid artery. The superior thyroid artery and the external branch of the superior laryngeal nerve were spotted and dissected.

The following parameters were studied: the origin, the route of the nerve, its reports with the superior thyroid artery and the superior pole of the thyroid gland.

\section{Results}

\section{Epidemiological characteristics of the anatomical subjects}

We realized 34 dissections of the external branch of the superior laryngeal nerve to 17 deathly subjects ( 11 men and 6 women with a sex-ratio of 1.8). The average age of the subjects was of 42 years (extremes: 18 and 70 years).

\section{Origin}

Our study allowed to highlight in $100 \%$ of the cases the external branch of the superior laryngeal nerve and the superior thyroid artery so to the right as to the left. 34 dissected external branch of the superior laryngeal nerve was born at the level of the big horn of the bone hyoid. The superior thyroid arteries approached the side lobe of the thyroid gland at the level of its cranial pole.

\section{Routes and reports}

On 34 dissected external branch of the superior laryngeal nerve, none had a previous route (Tables 1-3; Figures 1-6). However we found 28 nerves (that is 82.4\%) having a later route, stuck to the external face of the lower constrictor of the pharynx. These were not mixed with the superior thyroid artery and its branch of division and were situated outside the thyroid capsule.

In $17.6 \%$ of the cases ( 6 BENLS), the nerve had a route mixed in the branch of the superior thyroid artery. These were found inside of the capsule $(11.8 \%$ adhered to the artery and $5.8 \%$ crossed its branch of division).

In our study, the nerve is distant from the artery in $31.25 \%$ of the cases between 0 in $0.5 \mathrm{~cm}$. This constitutes a distance at risk.

Table 1. Distribution of the cases according to the route of the external branch of the superior laryngeal nerve.

\begin{tabular}{ccccc}
\hline Route of the BENLS & Left & Right & Total & Percentage \\
\hline $\begin{array}{c}\text { Stuck to the external face of the lower constrictor of the } \\
\text { pharynx }\end{array}$ & 13 & 15 & 28 & $82.4 \%$ \\
Member in the superior thyroid artery (ATS) & 2 & 0 & 2 & $5.8 \%$ \\
Crossing the branch of the superior thyroid artery & 2 & 2 & 4 & $11.8 \%$ \\
Total & 17 & 17 & 34 & $100 \%$ \\
\hline
\end{tabular}

BENLS: external branch of the superior laryngeal nerve; ATS: superior thyroid artery. 
Table 2. Frequency of the external branch of the superior laryngeal nerve mixed and not mixed in the branch of division of the superior thyroid artery.

\begin{tabular}{ccccc}
\hline Arrangement of the BENLS with regard to the ATS & Left & Right & Total & Percentage \\
Mixed & 4 & 2 & 6 & $17.6 \%$ \\
Not mixed & 13 & 15 & 28 & $82.4 \%$ \\
Total & 17 & 17 & 34 & $100 \%$ \\
\hline
\end{tabular}

Table 3. Route of the external laryngeal nerve.

\begin{tabular}{|c|c|c|c|}
\hline \multirow{2}{*}{$\begin{array}{l}\text { Route of the external branch } \\
\text { of the superior laryngeal nerve }\end{array}$} & \multicolumn{3}{|c|}{ Authors } \\
\hline & Our study & N'guessan [1] & Page [3] \\
\hline $\begin{array}{l}\text { Stuck to the external face of the constrictor } \\
\text { of the pharynx }\end{array}$ & $82.4 \%$ & $75 \%$ & $80 \%$ \\
\hline Adhering to the superior thyroid artery & $11.8 \%$ & $18.75 \%$ & $20 \%$ \\
\hline Crossing the branches of the superior thyroid artery & $5.8 \%$ & $6.25 \%$ & \\
\hline
\end{tabular}

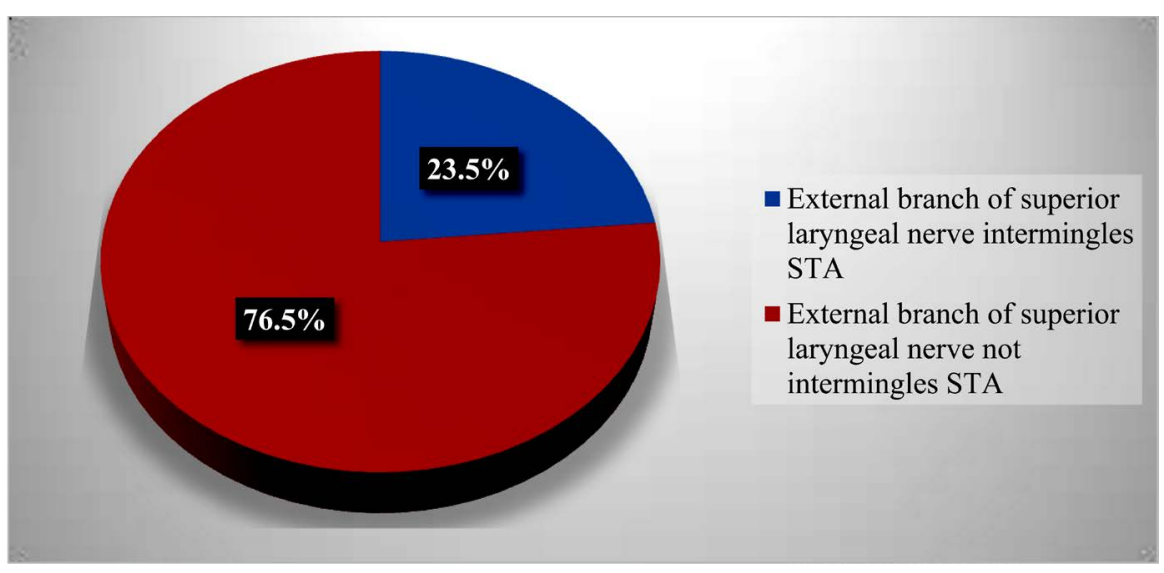

Figure 1. Frequency of the left external laryngeal nerves store or not store near the left superior thyroid artery division branch.

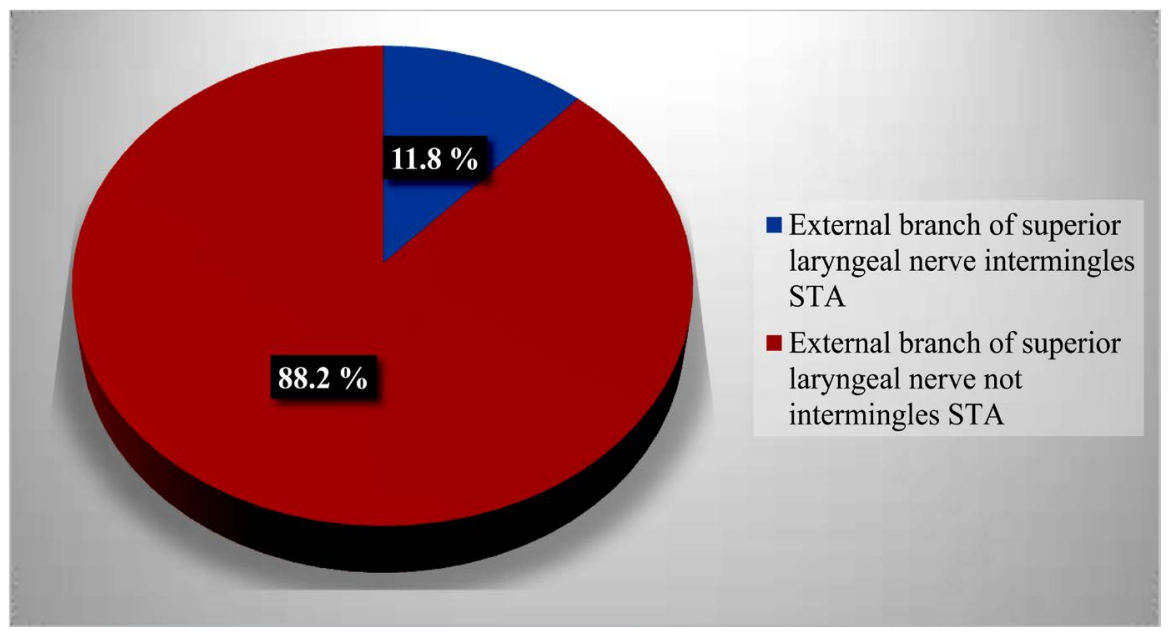

Figure 2. Frequency of the right external laryngeal nerves store or not store near the right superior thyroid artery division branch. 


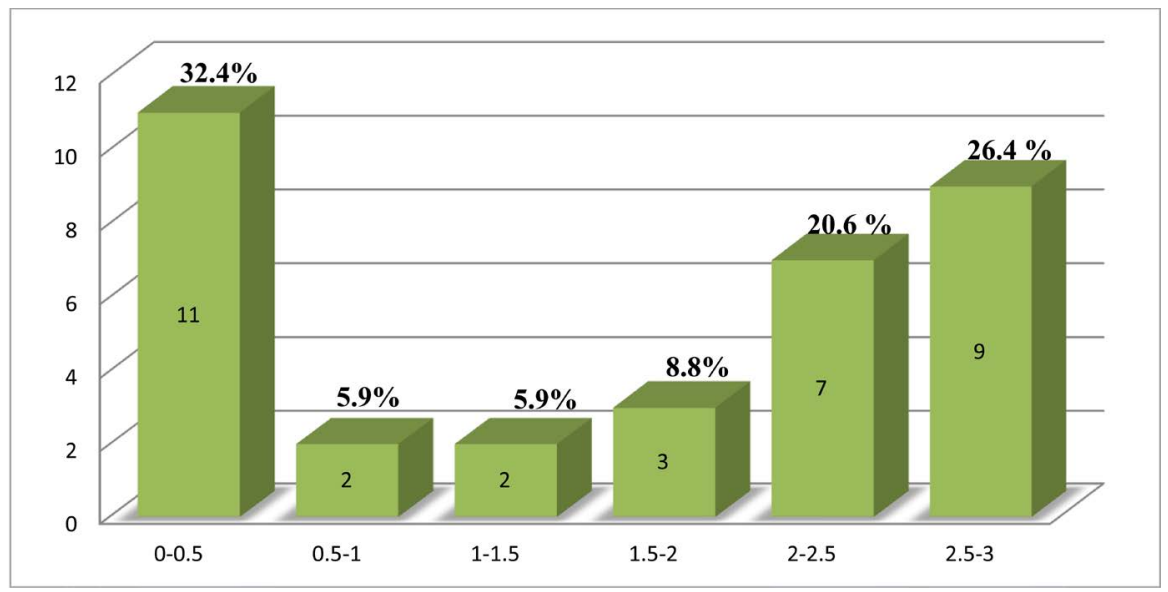

Figure 3. Distance between external laryngeal nerve and superior thyroid artery.

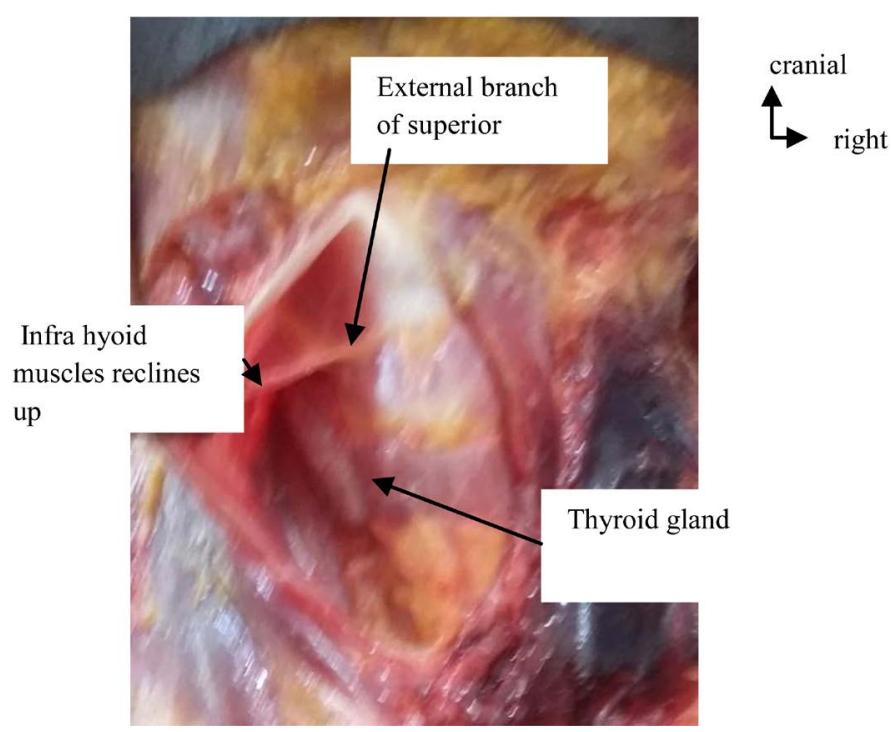

Figure 4. Anteriorsurgicalapproach.

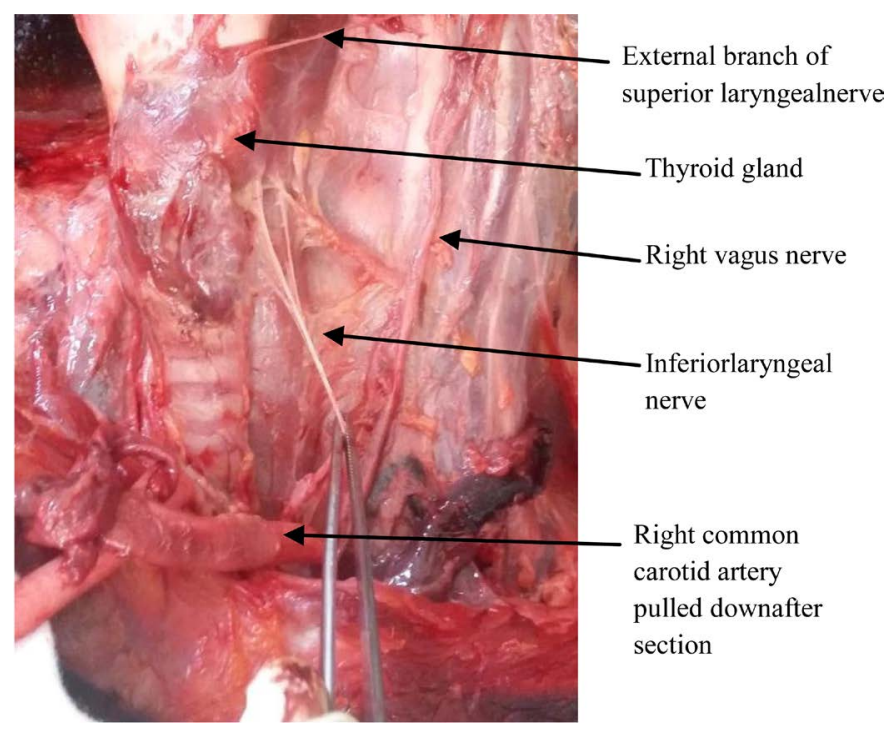

Figure 5. Trajectory of external branch of laryngeal nerve. 


\section{Discussion}

Numerous works realized on the external branch of the superior laryngeal nerve allowed describing multiple anatomical forms with variations of its origin, its route and these anatomical reports.

\section{Origin}

The external branch of the superior laryngeal nerve is classically considered as a branch of division or a collateral branch of the superior laryngeal nerve.

In our study, the dissections did not interest particularly its precise origin but it was in a macroscopic manner a branch stemming from the superior laryngeal nerve which was born at the level of the big horn of the bone hyoid in every case. This origin at the level of the big horn of the bone hyoid is the one brought back by most of the authors. However certain authors describe different origins or above big horn of the bone hyoid as Laux [1] or even an origin different from that of the superior laryngeal nerve [2] [3].

\section{Route}

During our study carrying 34 dissected nerves, in $82.4 \%$ of the cases the external branch of the superior laryngeal nerve was mixed in the superior thyroid artery and had a posterior route with regard to this one. It was stuck to the external face of the muscle lower constrictor of the pharynx. These anatomical measures offer more advantages to the surgeon because this one will have external branch of the superior laryngeal nerve not only distant from the superior thyroid artery but also from the superior thyroid capsule (18.75\% of the cases). The risk of hurting the external branch of the superior laryngeal nerve was real in $17.6 \%$ of the cases.

These results are almost identical to those of the series of Mossman and Dweese [4] and that of the Page and al [5].

In our study, the nerve has at the same time a route later and not mixed in the superior thyroid artery in $87.5 \%$ of the cases to the right and in $62.6 \%$ of the cases to the left.

Page et al. [5] in their dissections found that the nerve was accompanied on a short route by an arterio-venous pedicle in four cases on 30 and that there was an adhesion between the nerve and the trunk of the superior thyroid artery in four cases on 30, but on the other hand, they did not find case of nerve mixed in the superior thyroid pedicle while we found six cases on 34 that is $17.6 \%$ of cases of intermingling both quoted confused with especially cases to the right.

The risks of lesion of the external branch of the superior laryngeal nerve are defined by:

- an adhesion or an intermingling of the nerve with the superior thyroid vessels;

- a situation distal superficial of the nerve at the level of the cricothyroid muscle;

- the presence of a satellite vascular pedicle;

- the situation distal of the nerve between the larynx and the face interns of the thyroid lobe. 


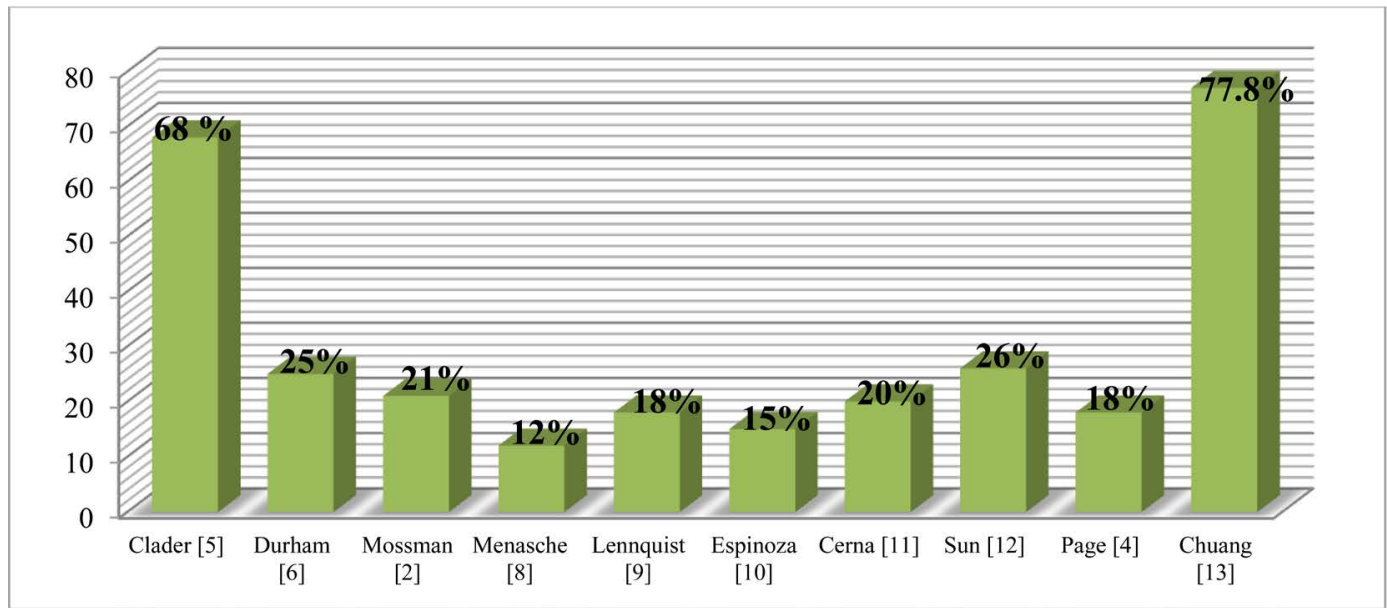

Figure 6. The external laryngeal nerves at surgical risk [2] [4] [5] [6] [8]-[13].

From these criteria, we estimated in our study that risks to hurt the external branch of the superior laryngeal nerve were $12.5 \%$ to the right and $37.5 \%$ to the left.

These risks were estimated by several authors whose results are presented in the (Figure 6).

Concerning the distance between the external branch of the superior laryngeal nerve and the superior thyroid artery, we found in $31,25 \%$ of the cases a distance at risk (between 0 in $0,5 \mathrm{cms}$ ) whereas Naidoo et al. [6] brought back this distance in $25 \%$ of the cases.

\section{Conclusions}

This study allowed us to estimate the risk of lesion of the BENLS. This risk is $25 \%$ whatever the type of thyroid surgery is. This risk is higher to the left than to the right.

The surgeon has to proceed to a meticulous and attentive dissection and recognize elements to be bound and to be cut by having in mind the possible anatomical variations [7]. To minimize the risk of lesion of the external branch of the superior laryngeal nerve, it is necessary to look for her by individualizing the superior thyroid artery and by dissecting up to the thyroid capsule.

\section{Conflicts of Interest}

We, authors of this article declare that there is no conflict of interests.

\section{References}

[1] N'guessan, L.K., Chatigrea, R., N’Da Koffi, D. and Kassanyou, S. (2010) Anatomical Variations of the External Laryngeal Nerve and the Thyroid Surgery: About 32 Dissections. Morphology, 94, 107-113.

[2] Moosman, D.A. and Deweese, S.M. (1968) The External Laryngeal Nerve as Related to Thyroidectomy. Surgery, Gynecology \& Obstetrics, 127, 1011-1016.

[3] Page, C., Laude, M., Peltier, J., Charlet, L., Ayache, S. and Strunski, V. (2004) 
Anatomy of the External Laryngeal Nerve: Surgical Implications. About 30 Dissections. Annales d Otolaryngologie et de Chirurgie Cervico-Faciale, 121, 148-155. https://doi.org/10.1016/S0003-438X(04)95502-8

[4] Page, C., Laude, M., Legars, D., Foulon, P. and Strunski, V. (2004) The External Laryngeal Nerve: Surgical and Anatomic Considerations. Report of 50 Total Thyroidectomies. Surgical and Radiologic Anatomy, 26, 182-185.

https://doi.org/10.1007/s00276-003-0214-y

[5] Clader, D.N., Luter, P.W. and Daniels, B.T. (1957) A Photographic Study of the Superior and Inferior Laryngeal Nerves and the Superior and Inferior Thyroid Arteries. The American Journal of Surgery, 23, 609-618.

[6] Durham, C.F. and Harrison, T.S. (1964) The Surgical Anatomy of the Superior Laryngeal Nerve. Obstetrics \& Gynecology, 118, 38-44.

[7] Barbin, J.Y., Visset, J. and Leborgne, J. (1976) The External Laryngeal Nerve. Bulletin de P Association des Anatomists (Nancy), 59, 1001-1012.

[8] Menasche, P., Mamoudy, P. and Blondeau, P. (1976) The External Laryngeal Nerve. Possible Danger of Thyroid Surgery. Study of Surgical Anatomy (Author's Translation). Annals of Surgery, 30, 121-129.

[9] Lennquist, S., Cahlin, C. and Smeds, S. (1987) The Superior Laryngeal Nerve in Thyroid Surgery. Surgery, 102, 999-1008.

[10] Espinoza, J., Hamoir, M. and Dhem, A. (1989) Preservation of the External Branch of the Superior Laryngeal Nerve in Thyroid Surgery. An Anatomic Study of 30 Dissections. Ann Otolaryngol Chir Cervicofac Journal, 6, 127-34.

[11] Cernea, C.R., Ferraz, A.R., Nishio, S., Dutra Jr., A., Hojaij, F.C. and Dos Santos, L.R. (1992) Surgical Anatomy of the External Branch of the Superior Laryngeal Nerve. Head Neck, 14, 380-383. https://doi.org/10.1002/hed.2880140507

[12] Sun, S.Q. and Dong, J.P. (1997) An Applied Anatomical Study of the Superior Laryngeal Nerve Loop. Surgical and Radiologic Anatomy, 19, 169-173. https://doi.org/10.1007/BF01627968

[13] Chuang, F.J., Chen, J.Y., Shyu, J.F., Su, C.H., Shyr, Y.M., Wu, C.W., et al. (2010) Surgical Anatomical of the External Branch of the Superior Laryngeal Nerve in Chinese Adults and Its Clinical Applications. Head Neck, 32, 53-57. 